\title{
Comparing the impact of active learning in a secondary school with research-led teaching in a medical school
}

\author{
A. Ravishankar ${ }^{1}$, A. Pritchard ${ }^{2}$, J. McNulty ${ }^{2}$, R. Breach ${ }^{2}$, S. E. E. Gates ${ }^{3}$, V. Wong ${ }^{4}$, S. McLaren ${ }^{2}$, \\ Y. Anderson ${ }^{2}$, A. Gilmour ${ }^{5}$ and M. R. Ritchie ${ }^{2,6}$ \\ ${ }^{1}$ University of London, London, UK, ${ }^{2}$ Arbroath High School, Arbroath, Angus, UK, ${ }^{3}$ Cambridge University, Cambridge, UK, \\ ${ }^{4}$ Aberdeen University, Aberdeen, UK, ${ }^{5}$ Manchester University, Manchester, UK and ${ }^{6}$ Napier University, Edinburgh, UK
}

Active learning in secondary schools is a process that encourages effective individual and group participation for a successful outcome during a learning situation. Research-led teaching in medical schools encourages students' learning through active participation in research in which a number of key skills can be developed, e.g. patient-based biomedical research. As a result of the involvement of school pupils in active learning and students in research-led teaching the learning experiences of the two groups may be similar. Involvement in such activities provides a wealth of opportunities for both pupils and undergraduate medical students through which they can gain a deeper understanding of the core subject matter and simultaneously further develop the range of core skills relevant for their future profession or career.

Senior pupils ( $n$ 10; five female and five male; age range 16-18 years) at Arbroath High School assisted with running a dietary intervention as part of a Learning Festival activity (a local council educational initiative in which the focus was 'health'), while preclinical students ( $n$ 8; four female and four male; age range 18-21 years) assisted with running a phase IV clinical trial at St Andrews University (St Andrews, UK), which is a method used to monitor the effect of a medicine once it is in use. The aim of the present study was to evaluate the effect of participation on pupils' and students' learning across a range of skills and compare the impact on learning and skills acquisition for active learning $v$. a research-led teaching approach.

Students and pupils identified six key skills that were used during the execution of each activity. These six key skills were identified as being constituents of core skills in the medical curriculum at St Andrews University. Confidence in each skill was measured at the start and end of the activity using a questionnaire which contained a linear analogue scale, numbers 1 to 10 where 10 was regarded as the maximum. A Student's $t$ test (two-tailed) was used to assess the significance of the difference in scores for each skill.

\begin{tabular}{|c|c|c|c|c|c|}
\hline \multicolumn{3}{|c|}{ Medical students } & \multicolumn{3}{|c|}{ School pupils } \\
\hline Skill & $n$ & $P$ & Skill & $n$ & $P$ \\
\hline Blood pressure measurement & 7 & $<0.001$ & Resource management & 10 & $<0.001$ \\
\hline Venepuncture & 8 & $<0.05$ & Organisational & 10 & $<0.05$ \\
\hline Communication & 8 & 0.001 & Communication & 10 & $<0.0$ \\
\hline Management & 7 & $<0.05$ & Management & 10 & $<0.001$ \\
\hline Personal and interpersonal & 8 & 0.001 & Personal and interpersonal & 10 & 0.01 \\
\hline Research & 8 & 0.001 & Research & 10 & $<0.001$ \\
\hline
\end{tabular}

The results indicate the impact of participation in active learning and research-led teaching ${ }^{(1)}$ (S Gates et al. unpublished results) was significant in the acquisition of skills for both school pupils and medical students. Interestingly, many skills were common to both students and school pupils. The most significant effect for both groups was noted in a specific task such as venepuncture $v$. resource management and research skills, while communication skills and personal and interpersonal skills were also significantly influenced. As far as the authors are aware the present study is the first to compare the impact of research-led teaching in medicine and active learning in secondary education and demonstrate a significant impact on perceived acquisition of skills common to both.

1. Shek DT \& Wai CL (2008) Adolescence 43, 823-845. 